\title{
1,25-Dihydroxyvitamin D3 Inhibits the RANKL Pathway and Impacts on the Production of Pathway-Associated Cytokines in Early Rheumatoid Arthritis
}

\author{
Jing Luo, ${ }^{1}$ Hongyan Wen, ${ }^{1}$ Hui Guo, ${ }^{2}$ Qi Cai, ${ }^{3}$ Shuangtian Li, ${ }^{4}$ and Xiaofeng Li ${ }^{1}$ \\ ${ }^{1}$ Division of Rheumatology, Department of Medicine, The Second Hospital of Shanxi Medical University, Taiyuan, \\ Shanxi 030001, China \\ ${ }^{2}$ Department of Medicine, The Second Hospital of Shanxi Medical University, Taiyuan, Shanxi 030001, China \\ ${ }^{3}$ Arizona Health Sciences Center, 1501 N. Campbell, Room 4104, P.O. Box 245051, Tucson, AZ 85724, USA \\ ${ }^{4}$ University of Washington, 1410 NE Campus Parkway, 459 Schmitz Hall, P.O. Box 355832, Seattle, WA 98195-5832, USA
}

Correspondence should be addressed to Xiaofeng Li; lixf2003@yahoo.com.cn

Received 28 January 2013; Revised 1 April 2013; Accepted 3 April 2013

Academic Editor: Gary S. Stein

Copyright $\odot 2013$ Jing Luo et al. This is an open access article distributed under the Creative Commons Attribution License, which permits unrestricted use, distribution, and reproduction in any medium, provided the original work is properly cited.

Objectives. To study effects of 1,25-dihydroxyvitamin D3 $\left(1,25(\mathrm{OH})_{2} \mathrm{D}_{3}\right)$ on RANKL signaling pathway and pathway-associated cytokines in patients with rheumatoid arthritis (RA). Methods. Receptor activator of nuclear factor-kappa B ligand (RANKL), osteoprotegerin (OPG), IFN- $\gamma$, IL-6, TNF- $\alpha$, IL-17, and IL-4 were examined in 54 patients with incipient RA using a cytometric bead array (CBA) or an enzyme-linked immunosorbent assay (ELISA). Results. After 72 hours of incubation of peripheral blood mononuclear cells (PBMCs) with $1,25(\mathrm{OH})_{2} \mathrm{D}_{3}$ in RA patients, the levels of RANKL, TNF- $\alpha$, IL-17 and IL-6 significantly decreased compared to those of the control. $1,25(\mathrm{OH})_{2} \mathrm{D}_{3}$ had no significantly impact on the levels of OPG, RANKL/OPG, and IL-4. Conclusions. The present study demonstrated that $1,25(\mathrm{OH})_{2} \mathrm{D}_{3}$ reduced the production of RANKL and the secretion of TNF$\alpha$, IL-17, and IL-6 in PBMCs of RA patients, which indicated that $1,25(\mathrm{OH})_{2} \mathrm{D}_{3}$ might be able to decrease damage of cartilage and bone in RA patients by regulating the expression of RANKL signaling pathway and pathway-associated cytokines.

\section{Introduction}

Rheumatoid arthritis (RA) is a common chronic autoimmune disorder characterized by synovial inflammation. Bone loss in the inflamed joints $[1,2]$ occurs in the early stage of the disease, followed by the destruction of articular cartilage and bones. During the processing of the disease, the signaling pathway of receptor activator of nuclear factor kappa-B ligand (RANKL) and osteoprotegerin (OPG) is crucial in osteoclasts differentiation and activation [3].

An abnormal proliferation of $\mathrm{T}$ lymphocytes is a characteristic of RA. Previous data indicate that the accumulation and proliferation of $\mathrm{T}$ lymphocytes occurred prior to bone destruction $[4,5]$. T lymphocytes play a role in differentiation and maturation of osteoclasts [6]. T lymphocytes secrete soluble cytokines such as RANKL, macrophage colonystimulating factor (M-CSF), and tumor necrosis factor- $\alpha$
(TNF- $\alpha$ ) and thereby directly induce the formation and differentiation of osteoclasts (direct effect) [7-9]. In addition, T lymphocytes produce interleukins such as IL-1, IL-6, and IL-17, which are absorption-promoting cytokines stimulating the expression of RANKL on the cell surface of mature osteoclasts, mesenchymal cells, or fibroblasts [10-12].

Subsequently, binding of RANKL to its specific receptor, receptor activator of nuclear factor kappa-B (RANK) on the surface of preosteoclasts, further increases differentiation, and maturation of osteoclasts [12]. Therefore, the published data suggest a close correlation between the RANKL pathway and joint deterioration in RA patients [13].

It is well known that 1,25-dihydroxyvitamin D3 $\left(1,25(\mathrm{OH})_{2} \mathrm{D}_{3}\right)$ plays an important role in the bone formation [14]. Currently, studies have suggested that $1,25(\mathrm{OH})_{2} \mathrm{D}_{3}$ is also an important immune modulator [15]. It has been demonstrated that $1,25(\mathrm{OH})_{2} \mathrm{D}_{3}$ directly inhibits T-cell 
proliferation and reduces its secretion of IL-2 and IFN- $\gamma$ [16]. However, it is unclear whether $1,25(\mathrm{OH})_{2} \mathrm{D}_{3}$ is involved in the regulation of RANKL signaling pathway.

In the present study, using RA patients and healthy control peripheral blood mononuclear cells (PBMCs), we studied effects of $1,25(\mathrm{OH})_{2} \mathrm{D}_{3}$ on RANKL signaling pathway and associated cytokines. Methotrexate (MTX) was a common drug used in the treatment of RA because of its role of immune modulation [17]. Therefore, the effects of combination of $1,25(\mathrm{OH})_{2} \mathrm{D}_{3}$ and MTX on the RANKL signaling pathway as well as associated cytokines were also investigated.

\section{Materials and Methods}

2.1. Subjects. 54 incipient RA patients were recruited from the department of Rheumatology of the Second Hospital of Shanxi Medical University, including 18 males and 36 females with an age between 30 to 65 years old. They all fulfilled the American College of Rheumatology revised criteria for RA [18]. None of the patients had ever used vitamin D, glucocorticoids, immunosuppressants, or a tumor necrosis factor antagonist prior to the study. All patients had normal liver and kidney functions. 18 healthy volunteers were used as healthy control, and gender and age were completely matched to the RA patients. This study was approved by the Research Ethics Committee of the Second Hospital of Shanxi Medical University.

2.2. Sample Collection. $18 \mathrm{~mL}$ peripheral venous blood was collected from fasting subjects in the early morning. $15 \mathrm{~mL}$ was placed in a tube with heparin sodium anticoagulant for extracting the peripheral blood mononuclear cells (PBMCs), and the remaining $3 \mathrm{~mL}$ for extracting serum was placed in a tube without any anticoagulant. The blood samples without anticoagulant were kept at room temperature for 30 minutes to allow coagulating followed by centrifuging for $15 \mathrm{~min}$ at $1,000 \mathrm{rpm}$. After centrifugation, the supernatants (serum) were removed and stored at $-80^{\circ} \mathrm{C}$ for future experiments.

2.3. In Vitro Stimulation and PBMCs Culture. Lymphocytes were isolated by density centrifugation from a $15 \mathrm{~mL}$ peripheral blood sample containing sodium heparin. Trypan blue staining was used to confirm that cell viability was $>95 \%$. The cells were suspended in phenol red-free Iscove's modified Dulbecco's medium (IMDM, Gibco, USA) supplemented with $10 \%$ charcoal-treated FCS, 100 units/mL penicillin, and $100 \mu \mathrm{g} / \mathrm{mL}$ streptomycin, and the cell suspension was prepared at a density of $2 \times 10^{6} / \mathrm{mL}$.

The healthy control and RA patients PBMCs were plated in a 96-well plate at $200 \mu \mathrm{L} /$ well and then treated with either vehicle (no stimulant) or the combination of anti-CD3 and anti-CD28 antibody plus $1,25(\mathrm{OH})_{2} \mathrm{D}_{3}$ at various concentrations $(\mathrm{D} 1=0.1 \mathrm{nM}$; D2 $=1 \mathrm{nM}$; D3 $=100 \mathrm{nM})$, MTX at various concentrations $(\mathrm{M} 1=0.05 \mathrm{ug} / \mathrm{mL} ; \mathrm{M} 2=0.5 \mathrm{ug} / \mathrm{mL}$; $\mathrm{M} 3=1 \mathrm{ug} / \mathrm{mL})$, or with the combination of $1,25(\mathrm{OH})_{2} \mathrm{D}_{3}$ and MTX (D2M2 group). 1,25(OH) ${ }_{2} \mathrm{D}_{3}$ and/or MTX treatment was performed only in anti-CD3 and anti-CD28 antibody treated cells. For the vehicle control, no stimulant was added to the wells, which meant that anti-CD3, anti-CD28, MTX, and $1,25(\mathrm{OH})_{2} \mathrm{D}_{3}$ cannot be added to PBMCs. The final concentration of anti-CD3 was $300 \mathrm{ng} / \mathrm{mL}$ and of antiCD28 was $400 \mathrm{ng} / \mathrm{mL}$. For cells treated with 1,25(OH)2D3 and/or MTX, the cells were treated with $1,25(\mathrm{OH})_{2} \mathrm{D}_{3}$ and/or MTX plus anti-CD3 and anti-CD28 in a humidified, stabletemperature incubator at $37^{\circ} \mathrm{C}$ with $5 \% \mathrm{CO}_{2} 72$ hours after incubation, and the cultures were harvested by centrifuging at $2000 \mathrm{rpm}$ for 8 minutes. The supernatants were collected and stored at $-80^{\circ} \mathrm{C}$ for subsequent cytokines determination.

2.4. Measurement of RANKL, OPG, and Associated Cytokines in the Serum and Cell Culture Supernatant. The levels of RANKL and OPG were measured using ELISA (R\&D Co, Ltd.). Analysis of IFN- $\gamma$, IL-4, IL-6, TNF- $\alpha$, and IL-17 was conducted using a CBA human Th1/Th2/Th17 cytokine kit (BD Co, Ltd) and analyzed on a BDFACSCalibur flow cytometer. Quantity (pg/mL) of respective cytokine was calculated using CBA software.

\section{Statistical Analyses}

SPSS13.0 software was used for data analyses. All results were presented as mean \pm standard deviation $(M \pm S D)$. All data met the conditions for a normal distribution and homogeneity of variance. To compare two groups of data, a completely randomized, independent, two-sample $t$-test was used; to compare multiple groups of data, a one-way ANOVA method of square-deviation was applied, and either the Student-Newman-Keuls (SNK) test or the rank sum test was used to compare data among the groups. $P$ value $<0.05$ was considered to be significant.

\section{Results}

4.1. The Comparison of Serum Levels of RANKL, OPG and Associated Cytokines in RA Patients versus Healthy Control. We examined the expression of RANKL, OPG, and associated cytokines in the serum of RA patients and healthy control. Overall, there was a significant increase in RANKL, IL-17, IL6 , and TNF- $\alpha$ of RA patients when compared with those of healthy control (Table 1). Although OPG and RANKL/OPG showed a little increase in RA patients, no significant difference was observed. Further, the level of IL-4 was not significantly higher compared to that in healthy control.

4.2. The Levels of Anti-CD3 Plus Anti-CD28 Induced RANKL, $O P G$, and Associated Cytokines in the Culture Supernatant of RA and Healthy Control PBMCs. Anti-CD3/CD28 is the activator of $\mathrm{T}$ lymphocytes, and our data revealed that PBMCs of RA and healthy control cultured from freshly collected peripheral blood responded to the stimulation of anti-CD3 and anti-CD28 very well. The healthy control group and RA patients PBMCs were divided into vehicle control group and anti-CD3/CD28 group. In both RA and healthy control, after 72 hours stimulation, the levels of RANKL, TNF- $\alpha$, IL-17, IL-6, and IL- 4 in the anti-CD3/CD28 group 
TABLE 1: The serum levels of RANKL, OPG, and associated cytokines in RA patients versus control group.

\begin{tabular}{|c|c|c|c|c|c|c|c|}
\hline & $\begin{array}{l}\text { RANKL } \\
(\mathrm{pmol} / \mathrm{L})\end{array}$ & $\begin{array}{c}\mathrm{OPG} \\
(\mathrm{pmol} / \mathrm{L})\end{array}$ & RANKL/OPG & $\begin{array}{l}\text { TNF- } \alpha \\
(\mathrm{pg} / \mathrm{mL})\end{array}$ & $\begin{array}{c}\text { IL-17 } \\
(\mathrm{pg} / \mathrm{mL})\end{array}$ & $\begin{array}{c}\text { IL-6 } \\
(\mathrm{pg} / \mathrm{mL})\end{array}$ & $\begin{array}{c}\mathrm{IL}-4 \\
(\mathrm{pg} / \mathrm{mL})\end{array}$ \\
\hline RA group & $100.17 \pm 22.27$ & $0.64 \pm 0.17$ & $169.57 \pm 59.38$ & $5.91 \pm 2.53$ & $42.56 \pm 6.43$ & $16.63 \pm 12.00$ & $2.72 \pm 0.36$ \\
\hline Healthy control group & $75.82 \pm 9.108$ & $0.53 \pm 0.16$ & $149.00 \pm 26.71$ & $2.63 \pm 0.27$ & $21.10 \pm 3.22$ & $4.16 \pm 2.27$ & $2.72 \pm 0.33$ \\
\hline
\end{tabular}

Values are expressed as mean \pm standard deviation.

TABLE 2: The effect of Anti-CD3/CD28 induced the increases of inflammation-related cytokines in the PBMCs of RA and healthy control group.

\begin{tabular}{cccccccc}
\hline & $\begin{array}{c}\text { RANKL } \\
(\mathrm{pmol} / \mathrm{L})\end{array}$ & $\begin{array}{c}\text { OPG } \\
(\mathrm{pmol} / \mathrm{L})\end{array}$ & RANKL/OPG & $\begin{array}{c}\text { TNF- } \alpha \\
(\mathrm{pg} / \mathrm{mL})\end{array}$ & $\begin{array}{c}\mathrm{IL}-17 \\
(\mathrm{pg} / \mathrm{mL})\end{array}$ & $\begin{array}{c}\mathrm{IL}-6 \\
(\mathrm{pg} / \mathrm{mL})\end{array}$ & $\begin{array}{c}\mathrm{IL}-4 \\
(\mathrm{pg} / \mathrm{mL})\end{array}$ \\
\hline RA patient & & & & & & & \\
Vehicle control & $85.39 \pm 5.54$ & $0.53 \pm 0.13$ & $171.10 \pm 49.11$ & $12.55 \pm 5.32$ & $46.23 \pm 13.03$ & $2884.35 \pm 1389.03$ & $4.53 \pm 1.37$ \\
$\quad \begin{array}{l}\text { Anti-CD3/CD28 } \\
\text { 100.72 } \pm 11.98\end{array}$ & $0.57 \pm 0.15$ & $190.24 \pm 51.25$ & $508.52 \pm 90.94$ & $606.76 \pm 49.79$ & $7939.02 \pm 2108.85$ & $9.46 \pm 4.15$ \\
$\begin{array}{c}\text { Healthy control } \\
\text { Vehicle control }\end{array}$ & $67.22 \pm 11.14$ & $0.61 \pm 0.18$ & $127.18 \pm 14.07$ & $6.68 \pm 0.55$ & $25.48 \pm 3.78$ & $152.87 \pm 304.38$ & $5.02 \pm 2.53$ \\
Anti-CD3/CD28 & $83.09 \pm 12.17$ & $0.61 \pm 0.07$ & $136.23 \pm 13.42$ & $195.95 \pm 52.83$ & $249.87 \pm 17.63$ & $2607.90 \pm 232.98$ & $9.77 \pm 4.43$ \\
\hline
\end{tabular}

Values are expressed as mean \pm standard deviation.

significantly enhanced compared with the vehicle control group $(P<0.05$; Table 2$)$; although the level of OPG and RANKL/OPG in anti-CD3/CD28 group showed a little increase, the differences did not reach significance $(P>0.05$, Table 2).

4.3. The Levels of RANKL, OPG, and Associated Cytokines in the Culture Supernatant of RA Patients and Healthy Control' PBMCs Treated with MTX. MTX had been demonstrated to be one of the most effective agents in current use for the treatment of patients with active RA [19]. Healthy volunteers and RA patients' PBMCs were divided into anti-CD3/CD28 group and three different MTX-dose-treated groups M1, M2, and M3. Our data revealed that 72 hours after incubation of PBMCs with MTX in RA patients, the levels of RANKL, TNF- $\alpha$, IL-17 and IL- 6 significantly decreased in MTX treated groups compared with Anti-CD3/CD28 group in RA patients $(P<0.05$; Table 3; Figures 1, 2, 3, and 4). However, in three MTX treated groups, the inhibitions of pervious four cytokines were not in dose-dependent manner $(P>0.05$; Table 3). The treatment of MTX had no significant effect on the levels of OPG, RANKL/OPG and IL-4 in MTX testing groups compared to those in anti-CD3/CD28 group in RA patients $(P>0.05$; Table 3; Figures 5, 6, and 7). Further, in healthy control, there was no significant difference in all seven cytokines as mentioned above between the MTXtreated groups and anti-CD3/CD28 group $(P>0.05)$.

4.4. The Levels of RANKL, OPG, and Associated Cytokines in the Culture Supernatant of RA Patients and Healthy Control' PBMCs Treated with $1,25(\mathrm{OH})_{2} D_{3}$. To determine whether $1,25(\mathrm{OH})_{2} \mathrm{D}_{3}$ affected RANKL expression and associated cytokines, we tested three different doses of $1,25(\mathrm{OH})_{2} \mathrm{D}_{3}$ in anti-CD3/CD28-treated PBMCs of RA patients and healthy volunteers. $1,25(\mathrm{OH})_{2} \mathrm{D}_{3}$ treated groups were divided into $\mathrm{D} 1$,
$\mathrm{D} 2$, and D3. Our data revealed that 72 hours after incubation of PBMCs with $1,25(\mathrm{OH})_{2} \mathrm{D}_{3}$ in RA patients, the levels of RANKL, TNF- $\alpha$, IL-17 and IL- 6 significantly decreased in $1,25(\mathrm{OH})_{2} \mathrm{D}_{3}$ treated groups compared with anti-CD3/CD28 group $(P<0.05$; Table 3; Figures 1, 2, 3, and 4). However there was no significant difference in previous mentioned four cytokines expression in three different dose groups and the inhibitions were not in dose-dependent manner (Table 4). The treatment of $1,25(\mathrm{OH})_{2} \mathrm{D}_{3}$ had no significant effect on the levels of OPG, RANKL/OPG and IL-4 compared to antiCD3/CD28 group in RA patients $(P>0.05$; Table 4 ; Figures 5,6 , and 7). Further, in healthy control, there was no significant difference in all seven cytokines as mentioned above between $1,25(\mathrm{OH})_{2} \mathrm{D}_{3}$-treated groups and anti-CD3/CD28 group $(P>0.05)$.

4.5. The Levels of RANKL, OPG, RANKL/OPG, TNF- $\alpha, I L-6$ and IL-17 in the PBMCs Culture Supernatant of RA Patients and Healthy Control after Cotreatment with $1,25(\mathrm{OH})_{2} \mathrm{D}_{3}$ and MTX. To determine coeffect of $1,25(\mathrm{OH})_{2} \mathrm{D}_{3}$ and MTX, RA patients and healthy volunteers' PBMCs were divided into Anti-CD3/CD28 group and Anti-CD3/CD28+D2/M2 group. With the stimulation of anti-CD3/CD28, the cells were co-treated with MTX (M2) and $1,25(\mathrm{OH})_{2} \mathrm{D}_{3}(\mathrm{D} 2)$. Our data revealed that 72 hours after incubation of PBMCs with D2 M2 in RA, the levels of TNF- $\alpha$, IL-17 and IL6 significantly decreased compared with anti-CD3/CD28 group $(P<0.05$; Table 5; Figures 2, 3, and 4$)$ and the level of IL-4 in D2/M2 group significantly increased compared with Anti-CD3/CD28 group $(P<0.05$; Table 5; Figure 7). Our data demonstrated that, there were no significant change in the levels of RANKL, OPG, RANKL/OPG in D2M2-treated group compared to those in the anti-CD3/CD28 group in RA $(P>0.05$; Table 5, Figures 1, 5, and 6). Further, in healthy control, there was no significant difference in all seven 
TABLE 3: The impact of MTX at various concentrations on inflammation-related cytokines in RA and healthy control group.

\begin{tabular}{|c|c|c|c|c|c|c|c|}
\hline & $\begin{array}{l}\text { RANKL } \\
(\mathrm{pmol} / \mathrm{L})\end{array}$ & $\begin{array}{c}\text { OPG } \\
(\mathrm{pmol} / \mathrm{L})\end{array}$ & RANKL/OPG & $\begin{array}{l}\text { TNF- } \alpha \\
(\mathrm{pg} / \mathrm{mL})\end{array}$ & $\begin{array}{c}\text { IL-17 } \\
(\mathrm{pg} / \mathrm{mL})\end{array}$ & $\begin{array}{c}\text { IL-6 } \\
(\mathrm{pg} / \mathrm{mL})\end{array}$ & $\begin{array}{c}\text { IL-4 } \\
(\mathrm{pg} / \mathrm{mL})\end{array}$ \\
\hline \multicolumn{8}{|l|}{ RA patient } \\
\hline Anti-CD3/CD28 & $100.72 \pm 11.98$ & $0.57 \pm 0.15$ & $190.24 \pm 51.25$ & $508.52 \pm 90.94$ & $606.76 \pm 49.79$ & $7939.02 \pm 2108.85$ & $9.46 \pm 4.15$ \\
\hline M1 & $77.60 \pm 7.61$ & $0.44 \pm 0.05$ & $175.62 \pm 21.61$ & $318.81 \pm 74.45$ & $451.50 \pm 50.08$ & $5255.36 \pm 4309.03$ & $16.30 \pm 11.6$ \\
\hline M2 & $82.57 \pm 11.23$ & $0.50 \pm 0.06$ & $164.74 \pm 18.24$ & $292.46 \pm 58.67$ & $372.13 \pm 66.64$ & $7251.50 \pm 4455.93$ & $10.73 \pm 6.84$ \\
\hline M3 & $77.12 \pm 7.36$ & $0.57 \pm 0.13$ & $139.14 \pm 29.05$ & $265.51 \pm 64.08$ & $315.10 \pm 103.73$ & $4706.41 \pm 3391.34$ & $14.13 \pm 9.24$ \\
\hline \multicolumn{8}{|l|}{ Healthy control } \\
\hline Anti-CD3/CD28 & $83.09 \pm 12.17$ & $0.61 \pm 0.07$ & $136.23 \pm 13.42$ & $195.95 \pm 52.83$ & $249.87 \pm 17.63$ & $2607.90 \pm 232.98$ & $6.77 \pm 4.43$ \\
\hline M1 & $71.02 \pm 16.39$ & $0.45 \pm 0.32$ & $158.02 \pm 38.89$ & $161.43 \pm 44.09$ & $204.60 \pm 21.31$ & $1952.67 \pm 355.35$ & $15.57 \pm 27.02$ \\
\hline M2 & $71.41 \pm 17.13$ & $0.53 \pm 0.06$ & $134.89 \pm 34.03$ & $144.53 \pm 24.13$ & $188.03 \pm 15.41$ & $2177.13 \pm 315.55$ & $16.15 \pm 11.55$ \\
\hline M3 & $80.49 \pm 24.10$ & $0.57 \pm 0.07$ & $140.29 \pm 42.54$ & $128.42 \pm 24.88$ & $187.83 \pm 41.34$ & $3823.98 \pm 2478.59$ & $7.38 \pm 2.82$ \\
\hline
\end{tabular}

Values are expressed as mean \pm standard deviation.

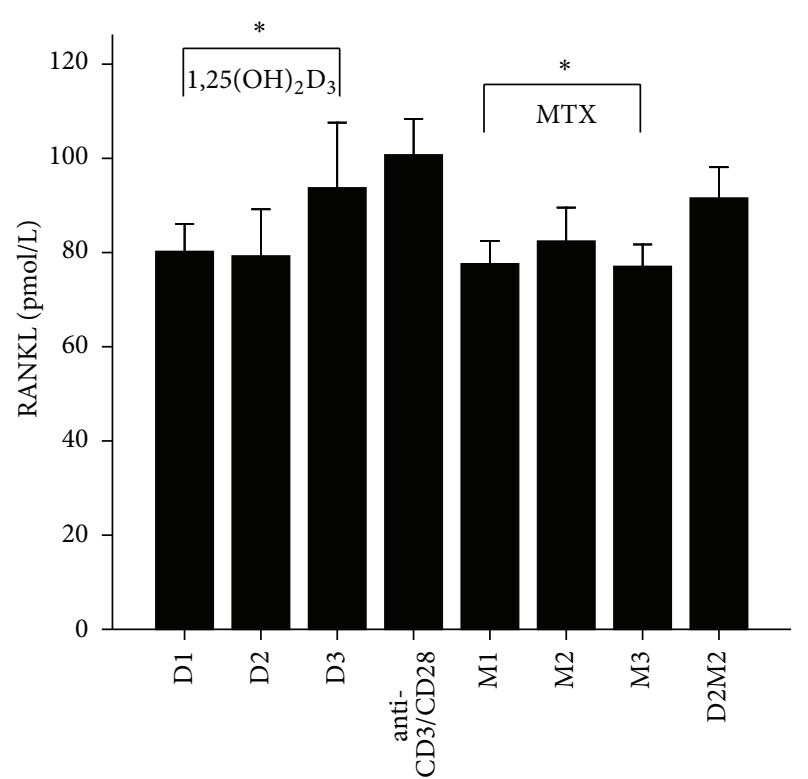

FIGURE 1: The levels of RANKL after treatment with $1,25(\mathrm{OH})_{2} \mathrm{D}_{3}$, MTX, and $1,25(\mathrm{OH})_{2} \mathrm{D}_{3}$ plus MTX in RA patients. The RA patients' PBMCs are treated with either anti-CD3/CD28, or $1,25(\mathrm{OH})_{2} \mathrm{D}_{3}$, MTX at various concentrations, or the combination of $1,25(\mathrm{OH})_{2} \mathrm{D}_{3}$ and MTX (D2M2 group). The levels of RANKL were detected and significantly decreased in the groups of $1,25(\mathrm{OH})_{2} \mathrm{D}_{3}$ and MTX compared to those of the group of anti-CD3/CD28 $(P<0.05)$. There was no difference in RANKL expression between the group of D2M2 and the group of Anti-CD3/CD28. ${ }^{*}$ Mean $P<0.05$.

cytokinesas mentioned above between the D2M2 treated group and Anti-CD3/CD28 group $(P>0.05)$.

\section{Discussion}

Rheumatoid arthritis (RA) is a common systemic autoimmune disease characterized by the destruction of articular cartilage and bone. Bone destruction was mediated by the

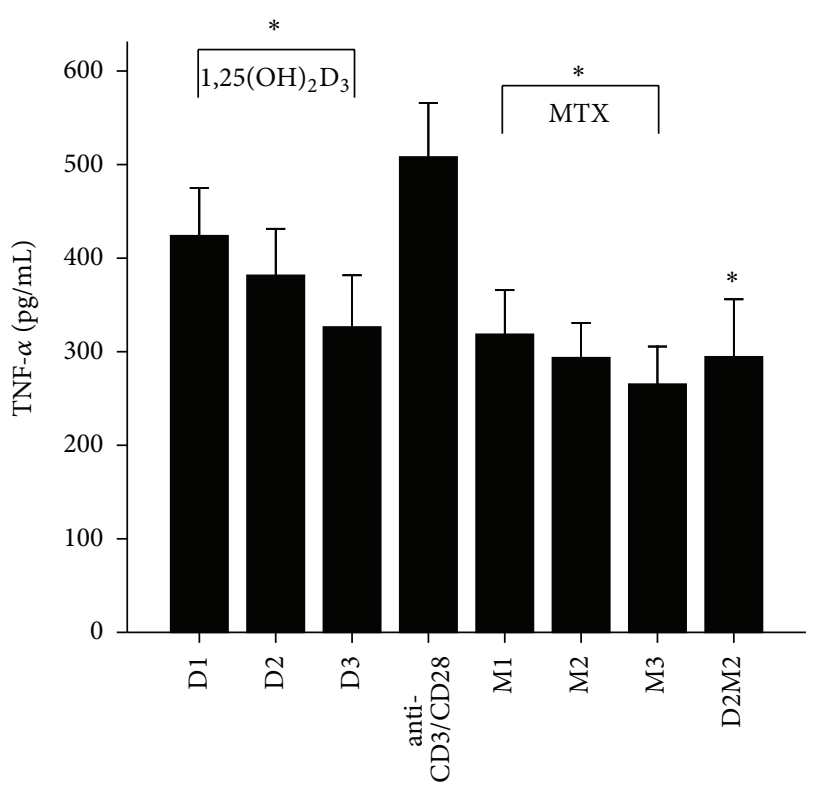

FIGURE 2: The levels of TNF- $\alpha$ after treatment with $1,25(\mathrm{OH})_{2} \mathrm{D}_{3}$, MTX, and $1,25(\mathrm{OH})_{2} \mathrm{D}_{3}$ plus MTX in RA patients. The RA patients' PBMCs treated with either anti-CD3/CD28, or $1,25(\mathrm{OH})_{2} \mathrm{D}_{3}$, MTX at various concentrations, or the combination of $1,25(\mathrm{OH})_{2} \mathrm{D}_{3}$ and MTX (D2M2 group). The level of TNF- $\alpha$ was detected and significantly decreased in the groups of $1,25(\mathrm{OH})_{2} \mathrm{D}_{3}$, MTX and D2M2 compared to the level in the group of anti-CD3/CD28 $(P<$ 0.05). * Mean $P<0.05$.

multinucleated giant cells, osteoclasts. It has been shown that osteoclasts were responsible for deterioration of joint function in RA patients [20]. The augmentation of RANKL secretion is indispensable for osteoclast differentiation [3, 4]. The ligation of RANKL to its receptor, RANK, on the cytoplasm membrane of osteoclasts, causes bone resorption and destruction. In addition, RANKL also increases the survival of mature osteoclasts and enhances their function and consequently increases bone destruction $[3,21,22]$. In 


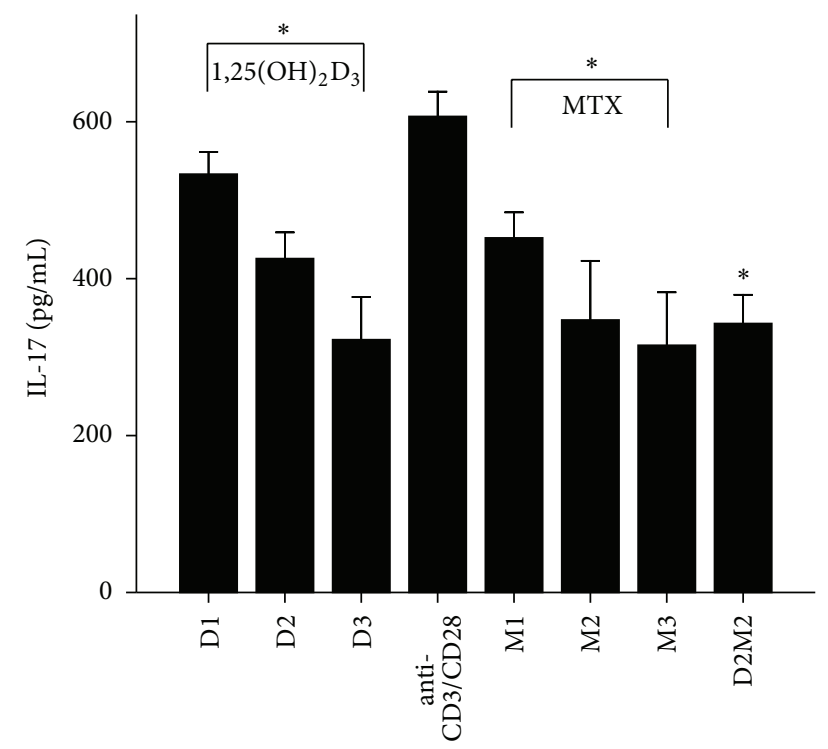

FIGURE 3: The levels of IL-17 after treatment with $1,25(\mathrm{OH})_{2} \mathrm{D}_{3}$, MTX, and $1,25(\mathrm{OH})_{2} \mathrm{D}_{3}$ plus MTX in RA patients. The RA patients' PBMCs are treated with either anti-CD3/CD28, 1,25(OH) ${ }_{2} \mathrm{D}_{3}$, MTX at various concentrations, or with the combination of $1,25(\mathrm{OH})_{2} \mathrm{D}_{3}$ and MTX (D2 M2 group). The RA patients' PBMCs treated with either Anti-CD3/CD28, or $1,25(\mathrm{OH})_{2} \mathrm{D}_{3}$ and MTX at various concentrations, or the combination of $1,25(\mathrm{OH})_{2} \mathrm{D}_{3}$ and MTX (D2M2 group). The levels of IL-17 were detected and significantly decreased in the groups of $1,25(\mathrm{OH})_{2} \mathrm{D}_{3}$, MTX and D2M2 compared to those of the group of anti-CD3/CD28 $(P<0.05) .{ }^{*}$ Mean $P<0.05$.

contrast, osteoprotegerin (OPG) is a soluble decoy receptor for RANKL by interfering with the RANKL/RANK binding, and it inhibits the maturation and activation of osteoclasts and their precursors $[21,22]$. Therefore, it was very important to investigate RANKL expression and how to maintain the balance between RANKL and OPG in RA patients, which might provide an insight on the new treatment in reducing or preventing joint destruction in RA patients. Consistent with this idea, in the present study, we found that, in serum of RA patients, RANKL expression substantially increased compared to that in healthy control; however, OPG expression and OPG/RANKL ratio did not reduce significantly, which was not consistent with the other report by Kim et al. [23]. It was remaining controversial whether the serum levels of OPG and OPG/RANKL reflected what was happening in bone and joints in patients. Possible explanation was that OPG in the serum of such patients was bound to a plasma protein(s) and thus rendered inactive [13], and further studies will be required to determine the significance of these observations. We noted increased production of RANKL, TNF- $\alpha$, IL-17, IL6 and IL-4, following stimulation of the PBMCs with antiCD3/anti-CD28, which suggested changes in the peripheral T-cell compartment. This finding indicated that the effect of anti-CD3/CD28 stimulation contributed to the increased cell activity in RA patients.

There is an increasing appreciation that vitamin $\mathrm{D}$ exert broad regulatory effects on cells of the innate and adaptive immune system. These include reducing antigen presentation

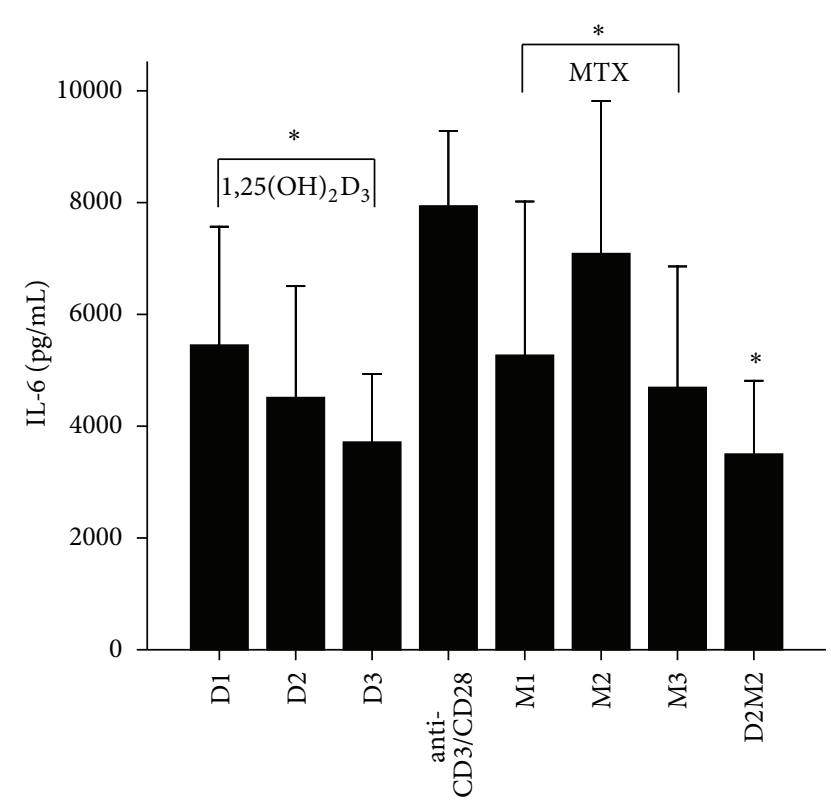

Figure 4: The levels of IL-6 after treatment with $1,25(\mathrm{OH})_{2} \mathrm{D}_{3}$, MTX, and $1,25(\mathrm{OH})_{2} \mathrm{D}_{3}$ plus MTX in RA patients. The RA patients' PBMCs are treated with either anti-CD3/CD28, or $1,25(\mathrm{OH})_{2} \mathrm{D}_{3}$, MTX at various concentrations, or the combination of $1,25(\mathrm{OH})_{2} \mathrm{D}_{3}$ and MTX (D2M2 group). The levels of IL-6 were detected and significantly decreased in the groups of $1,25(\mathrm{OH})_{2} \mathrm{D}_{3}, \mathrm{MTX}$, and D2M2 compared to those of the group of anti-CD3/CD28 $(P<$ 0.05). * Mean $P<0.05$.

through reducing the activity of dendritic cells or promoting their tolerogenic phenotype, affecting the polarization of monocytoid cells, altering B cell function, decreasing chemokine gradients and reducing tissue-specific homing [24-27]. A significant literature in humans also indicates that vitamin $\mathrm{D}$ increases the activity of regulatory $\mathrm{T}$ cells to prevent the excessive activation of autoreactive $\mathrm{T}$ cells $[28,29]$.

Previous report identified that RANKL mRNA expression was inhibited by 1,25-dihydroxyvitamin [30]. Our study demonstrated that the effect of $1,25(\mathrm{OH})_{2} \mathrm{D}_{3}$ treatment on RANKL expression in the RA group reached significance, although there was no significant dose-dependent effect. In contrast, $1,25(\mathrm{OH})_{2} \mathrm{D}_{3}$ treatment did not have a significant effect on OPG levels or the RANKL/OPG ratio. Therefore, $1,25(\mathrm{OH})_{2} \mathrm{D}_{3}$ might either suppress the synthesis or decrease secretion of RANKL in PBMCs of RA patients. A previous study demonstrated that vitamin $\mathrm{D}$ might have clinical implications in the treatment of prostate cancer [31]. In addition, we tested the hypothesis that $1,25(\mathrm{OH})_{2} \mathrm{D}_{3}$ might show therapeutic effect in RA patients through the down regulation of RANKL expression, given that RANKL was also expressed in the synovial cells of RA patients, and the drugs might work differently in vivo versus in vitro. Therefore, in future studies, we will perform the effect of $1,25(\mathrm{OH})_{2} \mathrm{D}_{3}$ on RANKL expression in synovial cells and the extend the study.

Identically, methotrexate (MTX) is widely utilized for the treatment of patients with RA. MTX inhibits the expression 


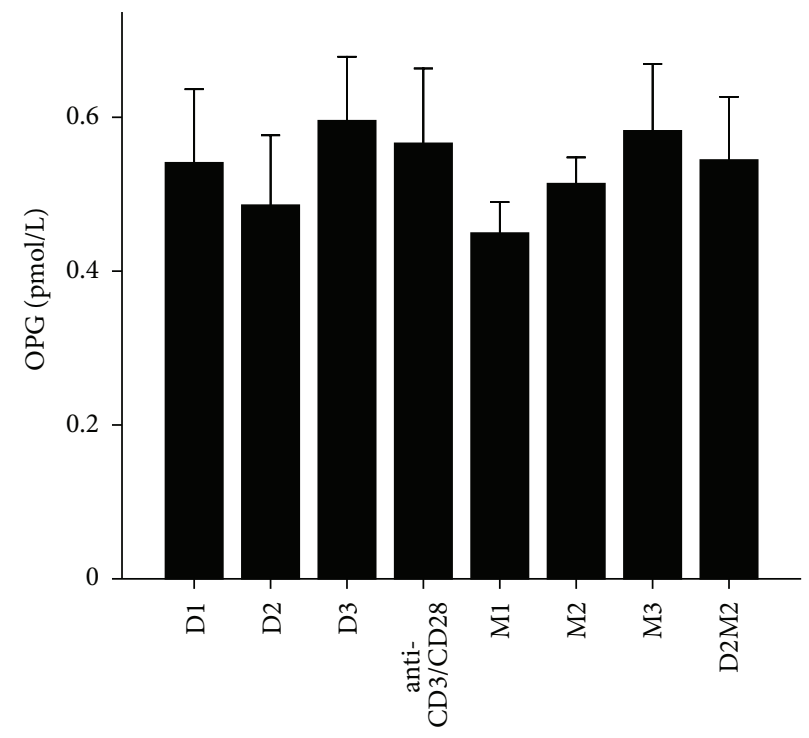

FIgure 5: The levels of OPG after treatment with $1,25(\mathrm{OH})_{2} \mathrm{D}_{3}, \mathrm{MTX}$, and $1,25(\mathrm{OH})_{2} \mathrm{D}_{3}$ plus MTX in RA patients. The RA patients' PBMCs are treated with either anti-CD3/CD28, or $1,25(\mathrm{OH})_{2} \mathrm{D}_{3}$ and MTX at various concentrations, or the combination of $1,25(\mathrm{OH})_{2} \mathrm{D}_{3}$ and $\mathrm{MTX}$ (D2M2 group). There was no difference in OPG expression between the groups of $1,25(\mathrm{OH})_{2} \mathrm{D}_{3}$, MTX, and D2M2 and the group of antiCD3/CD28 $(P>0.05)$.

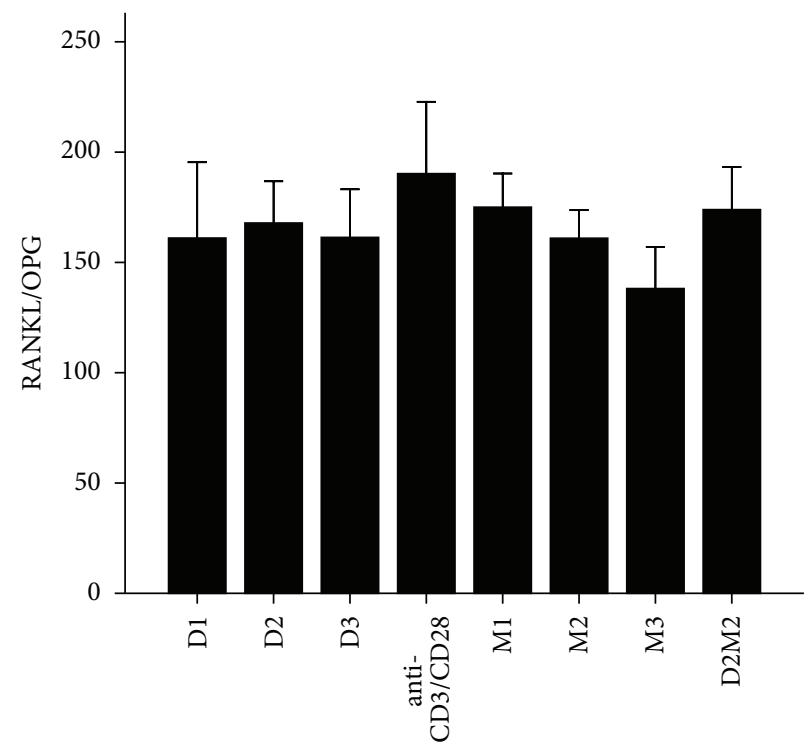

FIGURE 6: The levels of RANKL/OPG after treatment with $1,25(\mathrm{OH})_{2} \mathrm{D}_{3}, \mathrm{MTX}$, and $1,25(\mathrm{OH})_{2} \mathrm{D}_{3}$ plus MTX in RA patients. The RA patients' PBMCs are treated with either anti-CD3/CD28, or 1,25(OH) ${ }_{2} \mathrm{D}_{3}$ and MTX at various concentrations, or the combination of $1,25(\mathrm{OH})_{2} \mathrm{D}_{3}$ and MTX (D2M2 group). There was no difference in RANKL/OPG expression between the groups of 1,25(OH) ${ }_{2} \mathrm{D}_{3}, \mathrm{MTX}$, and D2M2 and the group of vehicle $(P>0.05)$.

of RANKL in RA patients in a dose-dependent manner, and also increases the secretion of OPG in RA supernatants [32]. In the present study, MTX treatment significantly decreased RANKL in the RA group. Although MTX decreased the expression of OPG and RANKL/OPG, this decline had no significant difference. Moreover, a higher MTX dose did not lead to a greater effect on the synthesis and secretion of RANKL, OPG or the RANKL/OPG ratio in patients' PBMCs. We postulated that MTX could effectively inhibit the synthesis and secretion of RANKL in RA patients' PBMCs. Cotreatment with $1,25(\mathrm{OH})_{2} \mathrm{D}_{3}+$ MTX reduced RANKL expression and the RANKL/OPG ratio; however, this reduction was not significant compared to MTX alone, indicating that further investigations were needed to determine the optimal dosage for both drugs.

It is well known that the cytokine expression pattern is correlated closely between local and systemic inflammation as well as bone reabsorption and bone density loss. The 


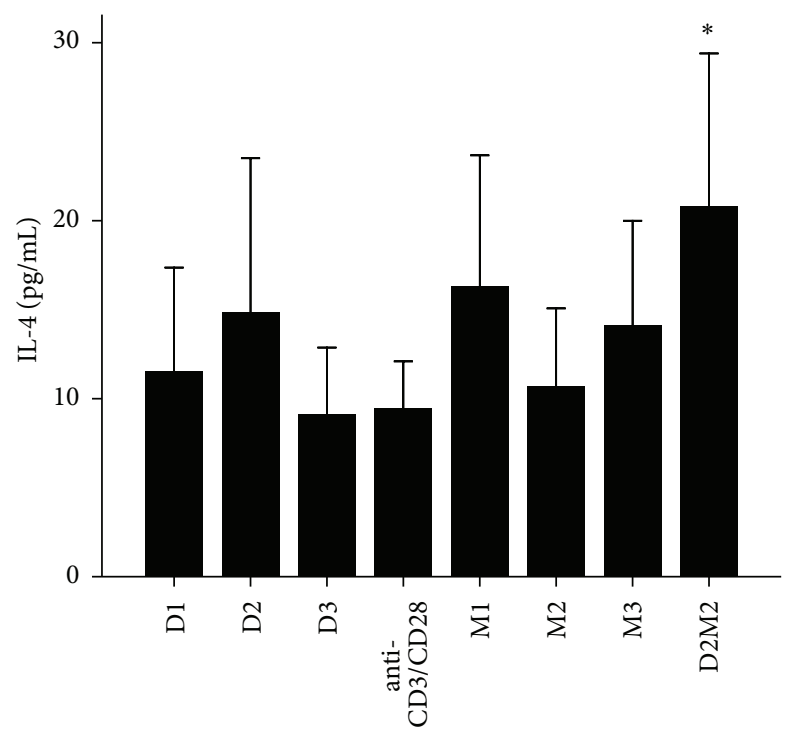

Figure 7: The levels of IL- 4 after treatment with $1,25(\mathrm{OH})_{2} \mathrm{D}_{3}$, MTX, and $1,25(\mathrm{OH})_{2} \mathrm{D}_{3}$ plus MTX in RA patients. The RA patients' PBMCs are treated with either anti-CD3/CD28, $1,25(\mathrm{OH})_{2} \mathrm{D}_{3}$ and MTX at various concentrations, or the combination of $1,25(\mathrm{OH})_{2} \mathrm{D}_{3}$ and MTX $(\mathrm{D} 2 \mathrm{M} 2$ group). $1,25(\mathrm{OH})_{2} \mathrm{D}_{3}$, MTX and $1,25(\mathrm{OH})_{2} \mathrm{D}_{3}$ plus MTX up-regulated the level of IL-4; however, there was no significant difference in IL-4 expression in the groups of $1,25(\mathrm{OH})_{2} \mathrm{D}_{3}$, MTX but there was significant difference in $\mathrm{D} 2 \mathrm{M} 2$ group $(P<0.05)$.

TABLE 4: The impact of $1,25(\mathrm{OH})_{2} \mathrm{D}_{3}$ at various concentrations on inflammation-related cytokines in the RA and healthy control group.

\begin{tabular}{|c|c|c|c|c|c|c|c|}
\hline & $\begin{array}{l}\text { RANKL } \\
(\mathrm{pmol} / \mathrm{L})\end{array}$ & $\begin{array}{c}\text { OPG } \\
(\mathrm{pmol} / \mathrm{L})\end{array}$ & RANKL/OPG & $\begin{array}{l}\text { TNF- } \alpha \\
(\mathrm{pg} / \mathrm{mL})\end{array}$ & $\begin{array}{c}\text { IL-17 } \\
(\mathrm{pg} / \mathrm{mL})\end{array}$ & $\begin{array}{c}\text { IL-6 } \\
(\mathrm{pg} / \mathrm{mL})\end{array}$ & $\begin{array}{c}\text { IL-4 } \\
(\mathrm{pg} / \mathrm{mL})\end{array}$ \\
\hline \multicolumn{8}{|l|}{ RA patient } \\
\hline Anti-CD3/CD28 & $100.72 \pm 11.98$ & $0.57 \pm 0.15$ & $190.24 \pm 51.25$ & $508.52 \pm 90.94$ & $606.76 \pm 49.79$ & $7939.02 \pm 2108.85$ & $9.46 \pm 4.15$ \\
\hline $\mathrm{D} 1$ & $80.23 \pm 9.37$ & $0.53 \pm 0.15$ & $163.92 \pm 56.07$ & $424.08 \pm 81.69$ & $533.35 \pm 47.47$ & $5513.03 \pm 3429.08$ & $11.56 \pm 9.14$ \\
\hline $\mathrm{D} 2$ & $79.01 \pm 15.41$ & $0.48 \pm 0.14$ & $167.83 \pm 29.43$ & $381.56 \pm 78.79$ & $425.75 \pm 55.33$ & $4554.65 \pm 3156.50$ & $14.83 \pm 13.65$ \\
\hline D3 & $93.75 \pm 21.88$ & $0.58 \pm 0.13$ & $164.90 \pm 35.68$ & $326.18 \pm 87.34$ & $318.91 \pm 85.91$ & $3747.55 \pm 1918.94$ & $9.13 \pm 5.88$ \\
\hline \multicolumn{8}{|l|}{ Healthy control } \\
\hline Anti-CD3/CD28 & $83.09 \pm 12.17$ & $0.61 \pm 0.07$ & $136.23 \pm 13.42$ & $195.95 \pm 52.83$ & $249.87 \pm 17.63$ & $2607.90 \pm 232.98$ & $6.77 \pm 4.43$ \\
\hline $\mathrm{D} 1$ & $82.43 \pm 10.19$ & $0.66 \pm 0.12$ & $129.67 \pm 30.01$ & $168.60 \pm 50.01$ & $219.48 \pm 35.87$ & $3229.37 \pm 2029.54$ & $7.27 \pm 1.56$ \\
\hline D2 & $15.46 \pm 8.95$ & $0.45 \pm 0.11$ & $175.07 \pm 39.69$ & $174.97 \pm 26.36$ & $211.48 \pm 41.78$ & $2601.70 \pm 1032.23$ & $9.47 \pm 6.57$ \\
\hline D3 & $74.67 \pm 12.61$ & $0.55 \pm 0.09$ & $139.44 \pm 30.40$ & $128.73 \pm 19.29$ & $206.53 \pm 27.70$ & $3236.45 \pm 862.95$ & $7.62 \pm 3.31$ \\
\hline
\end{tabular}

Values are expressed as mean \pm standard deviation.

TABLE 5: The impact of $1,25(\mathrm{OH})_{2} \mathrm{D}_{3}$ and MTX cotreatment on inflammation-related cytokines in the RA and healthy control group.

\begin{tabular}{|c|c|c|c|c|c|c|c|}
\hline & $\begin{array}{l}\text { RANKL } \\
(\mathrm{pmol} / \mathrm{L})\end{array}$ & $\begin{array}{c}\text { OPG } \\
(\mathrm{pmol} / \mathrm{L})\end{array}$ & RANKL/OPG & $\begin{array}{l}\text { TNF- } \alpha \\
(\mathrm{pg} / \mathrm{mL})\end{array}$ & $\begin{array}{c}\text { IL-17 } \\
(\mathrm{pg} / \mathrm{mL})\end{array}$ & $\begin{array}{c}\text { IL-6 } \\
(\mathrm{pg} / \mathrm{mL})\end{array}$ & $\begin{array}{c}\text { IL-4 } \\
(\mathrm{pg} / \mathrm{mL})\end{array}$ \\
\hline \multicolumn{8}{|l|}{ RA patient } \\
\hline Anti-CD3/CD28 & $100.72 \pm 11.98$ & $0.57 \pm 0.15$ & $190.24 \pm 51.25$ & $508.52 \pm 90.94$ & $606.76 \pm 49.79$ & $7939.02 \pm 2108.85$ & $9.46 \pm 4.15$ \\
\hline $\mathrm{D} 2 \mathrm{M} 2$ & $91.60 \pm 10.47$ & $0.54 \pm 0.13$ & $174.64 \pm 31.68$ & $294.4 \pm 97.24$ & $341.53 \pm 58.68$ & $3464.63 \pm 2061.39$ & $20.82 \pm 13.50$ \\
\hline \multicolumn{8}{|l|}{ Healthy control } \\
\hline Anti-CD3/CD28 & $83.09 \pm 12.17$ & $0.61 \pm 0.07$ & $136.23 \pm 13.42$ & $195.95 \pm 52.83$ & $249.87 \pm 17.63$ & $2607.90 \pm 232.98$ & $6.77 \pm 4.43$ \\
\hline $\mathrm{D} 2 \mathrm{M} 2$ & $70.44 \pm 13.01$ & $0.52 \pm 0.43$ & $136.28 \pm 27.89$ & $151.48 \pm 32.21$ & $197.98 \pm 43.97$ & $2427.27 \pm 238.13$ & $10.73 \pm 5.59$ \\
\hline
\end{tabular}

Values are expressed as mean \pm standard deviation. 
authors $[33,34]$ find that IL-6, IL-17, and TNF- $\alpha$ intensify the inflammation response, worsen local joint synovial inflammation, and finally lead to the acceleration of joint cartilage destruction. Moreover, there is a synergistic effect of IL-17 and TNF- $\alpha$ [33], particulary, during the early phase of RA, the levels of these two cytokines are closely associated with joint deterioration. Therefore, these cytokines are involved in bone and cartilage damage in RA patients. The RANKL-RANK system, together with its endogenous inhibitor, OPG, perhaps represents the most important regulation in the interaction between bones and cytokines [21]. IL-17 has a strong catabolic effect by increasing osteoclast production directly as well as indirectly through an alteration in OPG/RANKL system from the osteoblasts [35]. The RANKL-mediated enhancement of calcification of smooth muscle cell in the coculture with bone-marrow-derived macrophage was dependent on TNF$\alpha$ and IL-6 [36]. The evidence suggests that sIL-6R forms a complex with IL- 6 that has been induced by TNF- $\alpha$ or IL-17, and that the resulting IL-6/sIL-6R complex induces RANKL expression [34]. The expression of RANKL is regulated by proinflammatory cytokines such as TNF- $\alpha$, IL-6, and IL-17, which had demonstrated that the level of these cytokines is high in the serum and synovial fluid of RA patients $[33,34]$. The literatures also suggest that these cytokines can induce RANKL expression, which breaks the balance between RANKL and OPG, increasing the differentiation of osteoclast progenitor cells into mature osteoclasts in mice model of collagen-induced arthritis [34-36]. Our present study revealed that $1,25(\mathrm{OH})_{2} \mathrm{D}_{3}$ had a significant impact on the expression levels of TNF- $\alpha$, IL-17 and IL-6. These findings supported the idea that $1,25(\mathrm{OH})_{2} \mathrm{D}_{3}$ likely inhibited the expression of RANKL through reducing the synthesis and secretion of TNF- $\alpha$, IL-17, and IL-6 in RA patients' PBMCs, which eventually decreased bone erosion. MTX and cotreatment with $1,25(\mathrm{OH})_{2} \mathrm{D}_{3}+$ MTX had the same significant impact on the expression of RANKL, TNF- $\alpha$, IL-17, and IL-6. Our present study also suggested that $1,25(\mathrm{OH})_{2} \mathrm{D}_{3}$ or MTX treatment might affect the expression of RANKL or OPG through the inhibition of the aforementioned inflammationassociated cytokines and thus delay bone destruction. The further investigations will be needed to determine an optimal dose for each drug.

In summary, $1,25(\mathrm{OH})_{2} \mathrm{D}_{3}$ reduces whole-body bone loss and limits bone destruction in inflamed joints in RA patients. As an immunomodulatory drug, $1,25(\mathrm{OH})_{2} \mathrm{D}_{3}$ can be used in disease prevention without causing systemic immunosuppression. The present study demonstrates that $1,25(\mathrm{OH})_{2} \mathrm{D}_{3}$ reduces the production of RANKL and the secretion of TNF- $\alpha$, IL-17, and IL- 6 in PBMCs of RA patients, which indicates that $1,25(\mathrm{OH})_{2} \mathrm{D}_{3}$ might be able to decrease damage of cartilage and bone in RA patients by regulating the balance between proinflammatory and anti-inflammatory cytokines. Further studies are needed to be performed to test if $1,25(\mathrm{OH})_{2} \mathrm{D}_{3}$ directly affects the expression of RANKL and associated cytokines in cartilage or bone cells.

\section{Authors Contribution}

Jing Luo and Hongyan Wen contributed to this paper equally.

\section{Acknowledgments}

This work was supported by a Research Grant from the National Natural Science Foundation of China (no. 81273289/ H1008) and the Shanxi Scholarship council of China (no. 2008102).

\section{References}

[1] N. C. Walsh, T. N. Crotti, S. R. Goldring, and E. M. Gravallese, "Rheumatic diseases: the effects of inflammation on bone," Immunological Reviews, vol. 208, pp. 228-251, 2005.

[2] A. Stewart, L. M. Mackenzie, A. J. Black, and D. M. Reid, "Predicting erosive disease in rheumatoid arthritis. A longitudinal study of changes in bone density using digital X-ray radiogrammetry: a pilot study," Rheumatology, vol. 43 , no. 12 , pp. 1561-1564, 2004.

[3] W. J. Boyle, W. S. Simonet, and D. L. Lacey, "Osteoclast differentiation and activation," Nature, vol. 423, no. 6937, pp. 337-342, 2003.

[4] D. H. Jones, Y. Y. Kong, and J. M. Penninger, "Role of RANKL and RANK in bone loss and arthritis," Annals of the Rheumatic Diseases, vol. 61, no. 2, pp. ii32-ii39, 2002.

[5] I. E. Adamopoulos and E. P. Bowman, "Immune regulation of bone loss by Th17 cells," Arthritis Research and Therapy, vol. 10, no. 5, article 225, 2008.

[6] H. Takayanagi, "Osteoimmunology and the effects of the immune system on bone," Nature Reviews Rheumatology, vol. 5, pp. 667-676, 2009.

[7] N. J. Horwood, V. Kartsogiannis, J. M. W. Quinn, E. Romas, T. J. Martin, and M. T. Gillespie, "Activated T lymphocytes support osteoclast formation in vitro," Biochemical and Biophysical Research Communications, vol. 265, no. 1, pp. 144-150, 1999.

[8] Y. Choi, K. M. Woo, S. H. Ko et al., "Osteoclastogenesis is enhanced by activated $\mathrm{B}$ cells but suppressed by activated $\mathrm{CD} 8^{+}$ T cells," European Journal of Immunology, vol. 31, no. 7, pp. 21792188, 2001.

[9] S. M. Dai, H. Matsuno, H. Nakamura, K. Nishioka, and K. Yudoh, "Interleukin-18 enhances monocyte tumor necrosis factor $\alpha$ and interleukin-1 $\beta$ production induced by direct contact with T lymphocytes: implications in rheumatoid arthritis," Arthritis and Rheumatism, vol. 50, no. 2, pp. 432-443, 2004.

[10] S. Kotake, N. Udagawa, N. Takahashi et al., "IL-17 in synovial fluids from patients with rheumatoid arthritis is a potent stimulator of osteoclastogenesis," Journal of Clinical Investigation, vol. 103, no. 9, pp. 1345-1352, 1999.

[11] L. C. Hofbauer, D. L. Lacey, C. R. Dunstan, T. C. Spelsberg, B. L. Riggs, and S. Khosla, "Interleukin- $1 \beta$ and tumor necrosis factor$\alpha$, but not interleukin-6, stimulate osteoprotegerin ligand gene expression in human osteoblastic cells," Bone, vol. 25, no. 3, pp. 255-259, 1999.

[12] C. A. O’Brien, I. Gubrij, S. C. Lin, R. L. Saylors, and S. C. Manolagas, "STAT3 activation in stromal/osteoblastic cells is required for induction of the receptor activator of NF- $\kappa \mathrm{B}$ ligand and stimulation of osteoclastogenesis by gp130-utilizing cytokines or interleukin-1 but not 1,25-dihydroxyvitamin D3 or parathyroid hormone," Journal of Biological Chemistry, vol. 274, no. 27, pp. 19301-19308, 1999.

[13] B. F. Boyce and L. Xing, "Biology of RANK, RANKL, and osteoprotegerin," Arthritis Research and Therapy, vol. 9, supplement 1, article S1, 2007. 
[14] H. K. Nielsen, K. Brixen, M. Kassem, and L. Mosekilde, "Acute effect of 1,25-dihydroxyvitamin D3, prednisone, and 1,25dihydroxyvitamin D3 plus prednisone on serum osteocalcin in normal individuals," Journal of Bone and Mineral Research, vol. 6, no. 5, pp. 435-441, 1991.

[15] M. Cippitelli and A. Santoni, "Vitamin D3: a transcriptional modulator of the interferon-gamma gene," European Journal of Immunology, vol. 28, no. 10, pp. 3017-3030, 1998.

[16] S. C. Manolagas, D. A. Werntz, C. D. Tsoukas, D. M. Provvedini, and J. H. Vaughan, "1,25-dihydroxyvitamin D3 receptors in lymphocytes from patients with rheumatoid arthritis," Journal of Laboratory and Clinical Medicine, vol. 108, no. 6, pp. 596-600, 1986.

[17] J. A. M. Wessels, T. W. J. Huizinga, and H. J. Guchelaar, "Recent insights in the pharmacological actions of methotrexate in the treatment of rheumatoid arthritis," Rheumatology, vol. 47, no. 3, pp. 249-255, 2008.

[18] F. C. Arnett, S. M. Edworthy, D. A. Bloch et al., "The American rheumatism association 1987 revised criteria for the classification of rheumatoid arthritis," Arthritis and Rheumatism, vol. 31, no. 3, pp. 315-324, 1988 .

[19] J. M. Kremer, "Methotrexate therapy in the treatment of rheumatoid arthritis," Rheumatic Disease Clinics of North America, vol. 15, no. 3, pp. 533-556, 1989.

[20] S. L. Teitelbaum, "Bone resorption by osteoclasts," Science, vol. 289, no. 5484, pp. 1504-1508, 2000.

[21] N. Maruotti, M. Grano, S. Colucci, F. d'Onofrio, and F. P. Cantatore, "Osteoclastogenesis and arthritis," Clinical and Experimental Medicine, vol. 11, no. 3, pp. 137-145, 2011.

[22] S. Khosla, "Minireview: The OPG/RANKL/RANK system," Endocrinology, vol. 142, no. 12, pp. 5050-5055, 2001.

[23] H. R. Kim, S. H. Lee, and H. Y. Kim, "Elevated serum levels of soluble receptor activator of nuclear factors- $\kappa \mathrm{B}$ ligand (sRANKL) and reduced bone mineral density in patients with ankylosing spondylitis (AS)," Rheumatology, vol. 45, no. 10, pp. 1197-1200, 2006.

[24] R. Zhang and D. P. Naughton, "Vitamin D in health and disease: current perspectives," Nutrition Journal, vol. 9, no. 1, article 65, 2010.

[25] J. R. Moro, M. Iwata, and U. H. von Andriano, "Vitamin effects on the immune system: vitamins A and D take centre stage," Nature Reviews Immunology, vol. 8, pp. 685-698, 2008.

[26] L. B. Pedersen, F. E. Nashold, K. M. Spach, and C. E. Hayes, "1,25-Dihydroxyvitamin D3 reverses experimental autoimmune encephalomyelitis by inhibiting chemokine synthesis and monocyte trafficking," Journal of Neuroscience Research, vol. 85, no. 11, pp. 2480-2490, 2007.

[27] L. Adorini and G. Penna, "Control of autoimmune diseases by the vitamin D endocrine system," Nature Clinical Practice Rheumatology, vol. 4, pp. 404-412, 2008.

[28] J. Smolders, M. Thewissen, E. Peelen et al., "Vitamin D status is positively correlated with regulatory $\mathrm{T}$ cell function in patients with multiple sclerosis," PLoS ONE, vol. 4, no. 8, Article ID e6635, 2009.

[29] W. Royal, Y. Mia, H. Li, and K. Naunton, "Peripheral blood regulatory $\mathrm{T}$ cell measurements correlate with serum vitamin D levels in patients with multiple sclerosis," Journal of Neuroimmunology, vol. 213, no. 1-2, pp. 135-141, 2009.

[30] T. Suda, Y. Ueno, K. Fujii, and T. Shinki, "Vitamin D and bone," Journal of Cellular Biochemistry, vol. 88, no. 2, pp. 259-266, 2003.
[31] X. Y. Zhao, L. H. Ly, D. M. Peehl, and D. Feldman, "Induction of androgen receptor by $\alpha, 25$-dihydroxyvitamin D3 and 9cis retinoic acid in LNCaP human prostate cancer cells," Endocrinology, vol. 140, no. 3, pp. 1205-1212, 1999.

[32] C. K. Lee, E. Y. Lee, S. M. Chung, S. H. Mun, B. Yoo, and H. B. Moon, "Effects of disease-modifying antirheumatic drugs and antiinflammatory cytokines on human osteoclastogenesis through interaction with receptor activator of nuclear factor $\kappa \mathrm{B}$, osteoprotegerin, and receptor activator of nuclear factor $\kappa \mathrm{B}$ ligand," Arthritis and Rheumatism, vol. 50, no. 12, pp. 3831-3843, 2004.

[33] B. W. Kirkham, M. N. Lassere, J. P. Edmonds et al., "Synovial membrahe cytokine expression is predictive of joint damage progression in rheumatoid arthritis a two-year prospective study(the damage study cohort)," Arthritis and Rheumatism, vol. 54, no. 4, pp. 1122-1131, 2006.

[34] M. Hashizume, N. Hayakawa, and M. Mihara, "IL-6 transsignalling directly induces RANKL on fibroblast-like synovial cells and is involved in RANKL induction by TNF- $\alpha$ and IL-17," Rheumatology, vol. 47, no. 11, pp. 1635-1640, 2008.

[35] A. M. Tyagi, K. Srivastava, M. N. Mansoori, R. Trivedi, N. Chattopadhyay, and D. Singh, "Estrogen deficiency induces the differentiation of IL-17 secreting Th17 cells: a new candidate in the pathogenesis of osteoporosis," PLoS ONE, vol. 7, no. 9, Article ID e44552, 2012.

[36] K. A. Deuell, A. Callegari, C. M. Giachelli, M. E. Rosenfeld, and M. Scatena, "RANKL enhances macrophage paracrine procalcific activity in high phosphate-treated smooth muscle cells: dependence on IL-6 and TNF- $\alpha$," Journal of Vascular Research, vol. 49, no. 6, pp. 510-521, 2012. 


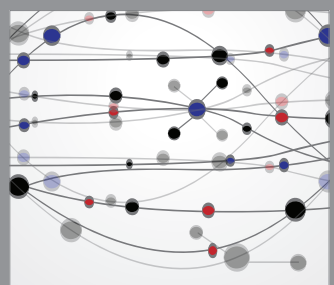

The Scientific World Journal
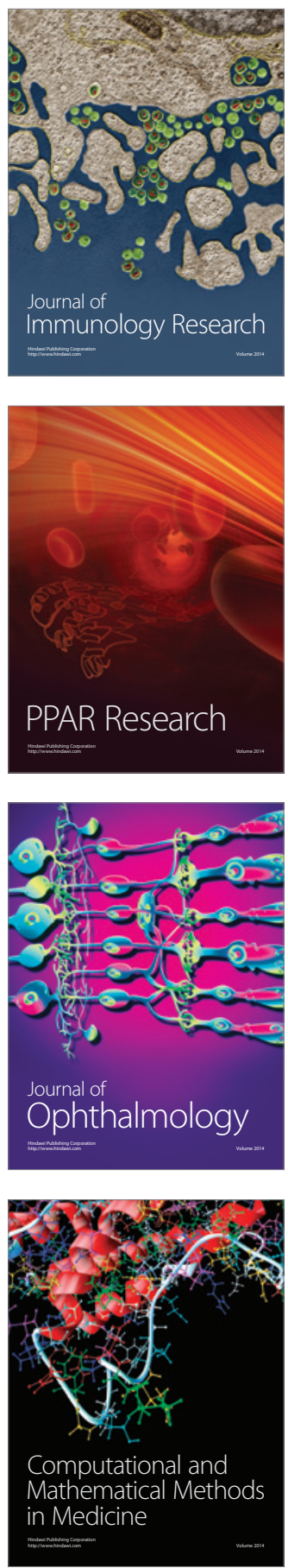

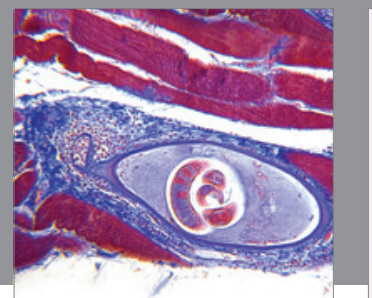

Gastroenterology

Research and Practice
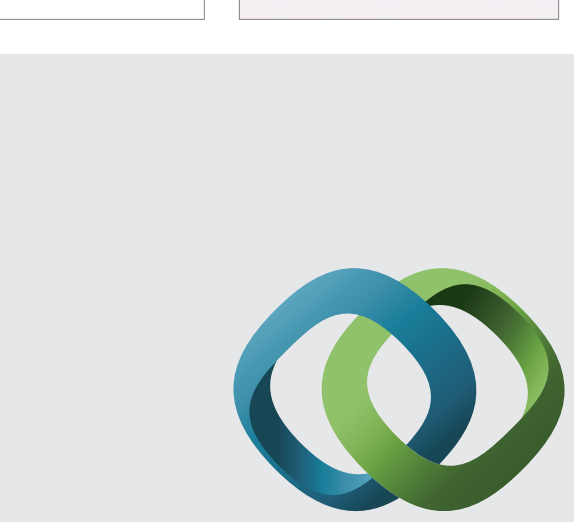

\section{Hindawi}

Submit your manuscripts at

http://www.hindawi.com
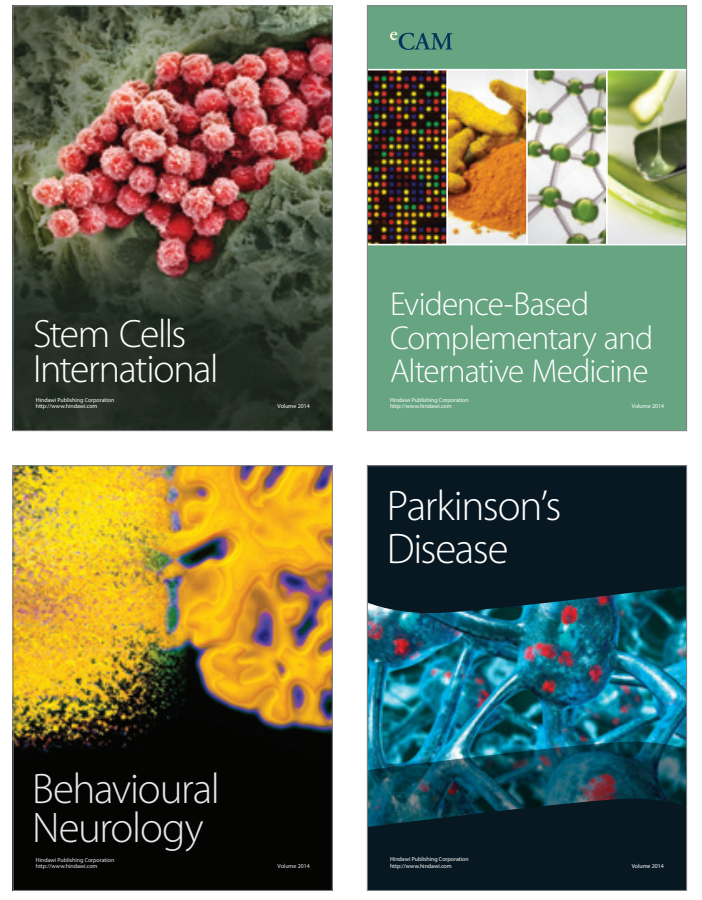
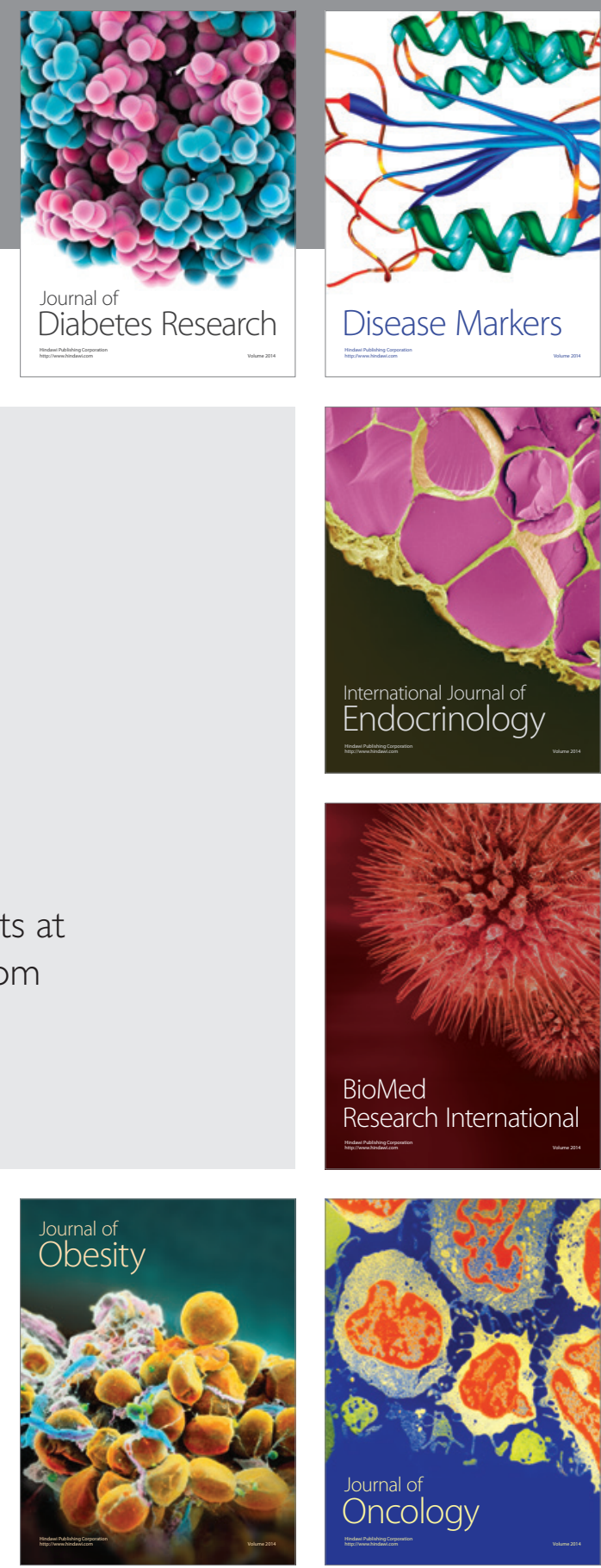

Disease Markers
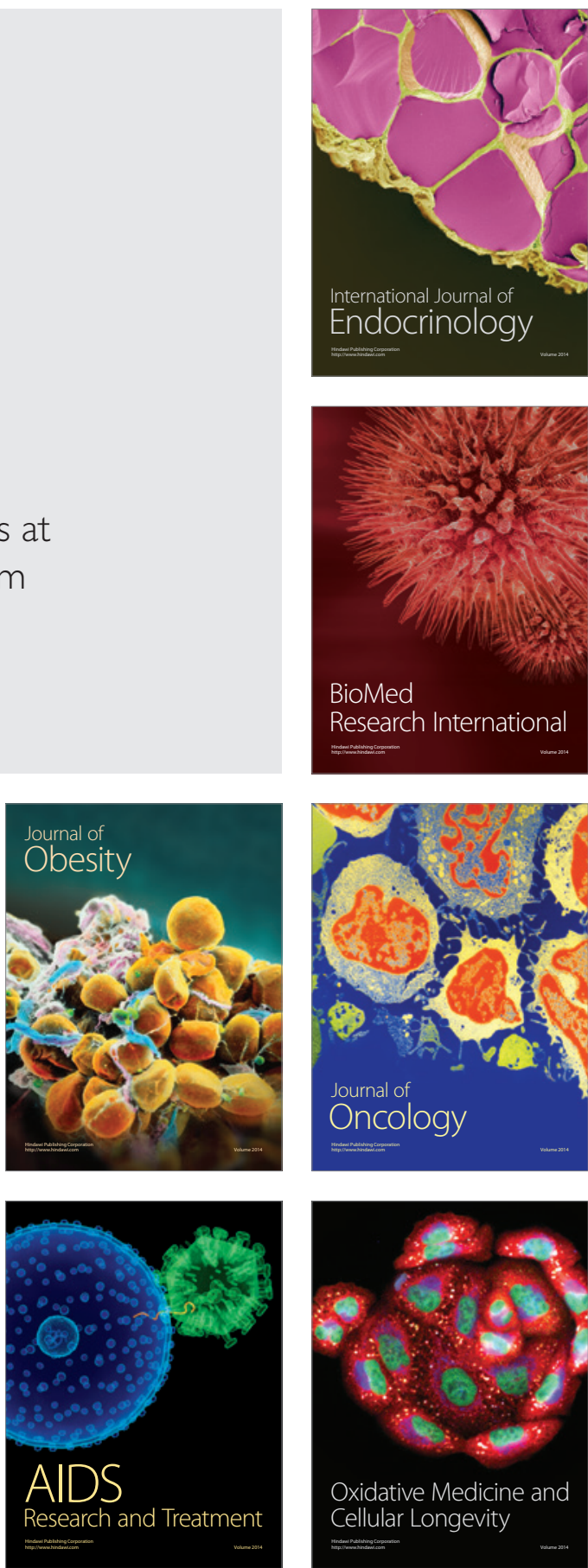